\title{
Nephroprotection of Withania somnifera root extract against gentamicin induced nephrotoxicity: a histological evaluation in experimental Wistar rats
}

\author{
Vimlesh Kushwaha*
}

Department of Pharmacology, G. C. R. G. Institute of Medical Science, Lucknow, Uttar Pradesh, India

Received: 04 September 2019 Revised: 18 September 2019 Accepted: 19 September 2019

\section{*Correspondence to:}

Dr. Vimlesh Kushwaha, Email: drvijv2008@gmail.com

Copyright: (C) the author(s), publisher and licensee Medip Academy. This is an openaccess article distributed under the terms of the Creative Commons Attribution NonCommercial License, which permits unrestricted noncommercial use, distribution, and reproduction in any medium, provided the original work is properly cited.

\begin{abstract}
Background: Gentamicin, an aminoglycoside group of drug, used against aerobic gram negative bacteria, is known for nephrotoxicity. Herbal products have a special place in the world of pharmaceuticals with their safety, efficacy and cost effectiveness. Withania somnifera (Ashwagandha) roots had known since long for its antioxidant status and free radical scavenging property. So $W$. somnifera can be used as nephroprotective agent because of free radical scavenging property.

Methods: Total 54 rats were randomised in 3 groups named G10, G20 and G30 according to 10, 20 and 30 days of treatment. In each groups, rats were randomly assigned to any of the three subgroups i.e., control $\mathrm{C}$ group [received normal saline $(2 \mathrm{ml} / 100 \mathrm{gm} / \mathrm{day})$ orally consecutively for test duration], gentamicin treated GT group [received normal saline $(2 \mathrm{ml} / 100 \mathrm{gm} /$ day $)$ orally consecutively for test duration and intraperitoneal gentamicin $(40 \mathrm{mg} / \mathrm{kg})$ once daily for last five days] and W. somnifera treated WST group [received $W$. somnifera orally $(500 \mathrm{mg} / \mathrm{kg} / \mathrm{day})$ for the test duration and intraperitoneal gentamicin $(40 \mathrm{mg} / \mathrm{kg}$ ) once daily for last five days]. Rats were sacrificed 24 hours after the last dose of gentamicin injection. Excised kidneys were weighted and prepared for histological examination.

Results: The mean weight of kidneys in GT group was significantly higher than the WST group in all test durations indicating the antioxidant and free radical scavenging property. This was also reflected histologically as WST group kidney showed less amount inflammation as compared to GT group.

Conclusions: $W$. somnifera root extract provide nephroprotection against gentamicin induced nephrotoxicity.
\end{abstract}

Keywords: Nephroprotection, Gentamicin, Withania somnifera, Ashwagandha, Tubular epithelium

\section{INTRODUCTION}

Aminoglycoside is a gram-negative antibacterial therapeutic agents that inhibit protein synthesis and contain an amino-modified glycoside sugar. ${ }^{1}$ Aminoglycoside is useful primarily in infections involving aerobic gram-negative bacteria, such as Pseudomonas, Acinetobacter and Enterobacter. Aminoglycoside are one of the important classes of antimicrobial agents which are used for more than 50 years. ${ }^{2}$ One important among them is gentamicin. Gentamicin has nephrotoxic potential. Gentamicin is well recognized to produce renal tubular necrosis mainly in the proximal tubule. Du et al found in their study that gentamicin enhanced superoxide anion and hydroxyl radical production in renal cortical mitochondria. They proposed a role of hydroxyl radicals in pathogenesis of gentamicin toxicity by inducing suppression of $\mathrm{Na}^{+} \mathrm{K}^{+}$ ATPase activity and DNA synthesis in proximal tubules. ${ }^{3}$ These processes results in accumulation of gentamicin in 
renal proximal convoluted tubules in a concentration, 50100 times greater than the serum. Thus serum half-life of aminoglycoside, which is few hours is prolonged (4-5 days in proximal tubule cells). ${ }^{4}$ This drug causes generation of reactive oxygen species, which induces cell injury and necrosis via lipid peroxidation. Administration of gentamicin leads to elevation in serum creatinine levels, urea levels, and renal tubular necrosis along with renal failure. ${ }^{5,6}$ Among several aminoglycoside antibiotics, the grade of nephrotoxicity caused has been reported to be in the following order as neomycin>gentamicin>tobramicin. ${ }^{7}$ Gentamicin nephrotoxicity occurs in about $15-30 \%$ of treated subjects.

Herbal products have a special place in the world of pharmaceuticals with their safety, efficacy and cost effectiveness. The World Health Organization found that $80 \%$ of the world's population depends on medicinal plants for their healthcare needs, and more than $30 \%$ of the pharmaceutical preparations are based on plants. ${ }^{8}$

Ashwagandha (Withania somnifera), also known as Indian winter cherry is an important ancient plant, the roots of which have been employed in Indian traditional systems of medicine, Ayurveda and Unani. In Sanskrit it is called Ashvagandha (asva 'horse', gandha 'smell') which means 'smell of the horse', because the root of the infected plant has the smell of the horse urine. ${ }^{9} \mathrm{~W}$. somnifera is a small, erect, evergreen woody under shrub belonging to Solanaceae family. The plant is chemically very complex and more than 80 compounds have been derived from it. It has been used in various diseases such as rheumatism, leprosy and arthritis. ${ }^{10}$ Among the other parts of this plant, the root has been considered to be the most active part for therapeutic purposes. The constituents of $W$. somnifera roots are the steroidal alkaloids and steroidal lactones. They belong to a class of constituents called the withanolides with the main active chemical constituent being withaferin A, a phytosteroid. ${ }^{11}$ Much of pharmacological activity in this plant has been attributed to two main withanolides i.e., withaferin $\mathrm{A}$ and withanolide D. ${ }^{12}$ Previously, Prakash et al stated that $W$. somnifera extract, for its antioxidant status and free radical scavenging property on 7, 12-dimethylbenz (a) anthracene, induced skin cancer in swiss albino mice. ${ }^{13}$

Ashwagandha can grow easily everywhere in India and its roots are known for antioxidant property since long, it can be used as nephroprotective drug against gentamicin induced nephrotoxicity. The present study was done to evaluate the nephroprotective action of the Ashwagandha root extract.

\section{Phytomorphology of Withania somnifera}

W. somnifera is a small or medium under shrub, 30-150 $\mathrm{cm}$ height, erect, greyish, branching perennial, with strong disagreeable odour like horse's urine coming from tuberous roots. The leaves are in an alternate manner (opposite on flowering shoots), normally broadly ovate. Flowers are generally small, greenish. Seeds are normally yellow. Withania somnifera can be identified by the red berry like fruit of about $6 \mathrm{~mm}$ size enclosed by the brownish, papery, turgid calyx. ${ }^{9}$

Ashwagandha can grow easily everywhere in India and its roots are known for antioxidant property since long, it can be used as nephroprotective drug against gentamicin induced nephrotoxicity. The present study was done to evaluate the nephroprotection action of the Ashwagandha root extract.

\section{METHODS}

This study was conducted in the Department of Pharmacology, L. L. R. M. Medical College, Meerut, UP, India from January 2015 to October 2015. Approval was taken from Institutional animal ethical committee. (Approval no. IAEC/2015/2 dated 14/5/15 of Lala Lajpat Rai Memorial Medical College, Meerut, India, registered under CPCSEA India (Registration No. $819 / 04 / \mathrm{ac} / \mathrm{CPCSEA})$. Total duration of study was ten months.

\section{Animal maintenance}

The certified pathogen-free healthy Albino Wistar rats of either sex, weighing about $180 \mathrm{gm}$, were obtained from the central animal house of the institute. The selected rats were kept under controlled temperature $\left(25^{\circ} \mathrm{C}\right)$ and alternating periods of light and darkness of 12 hours each. The rats had free access to standard rat pellet diet (Vet care India Ltd.) and tap water ad libitum. After seven days of acclimatization, rats were considered fit for study.

\section{Plant material}

W. somnifera (Ashwagandha) dry roots were procured from the Ayurveda medicinal shop in Meerut, Uttar Pradesh, India. The dry roots were identified and authenticated by the scientists in Botany Department of Chaudhary Charan Singh University, Meerut, (UP) India.

\section{Preparation of the root extract of $W$. somnifera}

The plant's root was dried for two days at $40^{\circ} \mathrm{C}$, crushed and powder was separated. Total 50 gram powder was mixed in $250 \mathrm{ml}$ of distilled water for 18 hours in a soxhlet apparatus. Extract of the root of W. somnifera in distilled water was collected. The extract was dried and stored at $0-4^{0} \mathrm{C}$. When needed the extract was suspended in water and used in the study. Aqueous extract of $W$. somnifera roots as a test drug was used.

\section{Estimation of LD50}

LD50 of $W$. somnifera root extract was determined on wistar rats by standard procedure. The acute oral toxicity study and estimation of LD50 was done according to the OECD guideline $423 .^{14}$ 


\section{Gentamicin}

Commercially available injectable preparation (Genticyn manufactured by Abbott Healthcare Pvt. Ltd.) was used to induce gentamicin nephrotoxicity.

\section{Experimental design}

Nephroprotection was evaluated for three periods of 10 , 20, 30 days durations and groups were named G10, G20, and G30 respectively. Rats were randomized in three groups of 18 rats each. Rats of each main groups were randomized to any of the three subgroups i.e., control (C), gentamicin treated (GT), W. somnifera treated (WST) groups of six rats each.

\section{Group C}

This was the control group and was given normal saline ( $2 \mathrm{ml} / 100 \mathrm{gm} /$ day) orally once a day, every day for test duration.

\section{Group $G T$}

In this group, normal saline ( $2 \mathrm{ml} / 100 \mathrm{gm} /$ day $)$ was given orally once a day consecutively for test duration and injection gentamicin (40 $\mathrm{mg} / \mathrm{kg})$ was injected intraperitoneally once daily for last five days.

\section{Group WST}

This group received $W$. somnifera orally $(500 \mathrm{mg} / \mathrm{kg} /$ day $)$ as a single dose in morning, before giving feed for the test duration and, injection gentamicin $(40 \mathrm{mg} / \mathrm{kg}$ ) was given intra-peritoneally once daily for last five days.

Rats were sacrificed 24 hours after the last dose of gentamicin injection (on $11^{\text {th }}, 21^{\text {st }}$ and $31^{\text {st }}$ day).

The test compounds were administered by the oral gavage method. Rats were fasted three to four hours prior to and one hour after administration. On the last day of study, rats of all groups were kept on fasting for 24 hours (tap water remained freely available) after which they were sacrificed under ketamine $(75 \mathrm{mg} / \mathrm{kg})$ and xylazine $(10 \mathrm{mg} / \mathrm{kg})$ anaesthesia given intra-peritoneally. ${ }^{15}$

The kidneys were excised from the animal and washed with the ice-cold saline. Kidneys were wiped with tissue paper and weighted immediately by electric balance analyser. After this, kidney was sectioned longitudinally in two halves and fixed in $10 \%$ buffered neutral formalin, dehydrated and cleared with graded alcohol and xylene respectively. This was followed by embedding in paraffin wax from which blocks were prepared. Sections of $5 \mu \mathrm{m}$ thickness were prepared from the blocks using a microtome. These were processed in alcohol xylene series and were stained with Harris haematoxylin and eosin stain and subjected to histopathological examination. $^{16}$

\section{Histopathological examination}

It was done in Pathology department under light microscope. Various structure of kidney were evaluated like congestion of glomerulus and tubule, epithelial desquamation, blood vessels congestion, interstitial edema, inflammatory cells, tubular casts and areas of necrosis.

Histological changes in kidney seen under light microscope after gentamicin induced toxicity were graded according to system adopted by Houghton et al. $^{17,18}$

Grade 0: Normal (-).

Grade 1: Tubular damage involving $<25 \%$ of cortical tubules $(+)$.

Grade 2: Tubular damage involving $25 \%$ and $<50 \%$ of cortical tubules (++).

Grade 3: Tubular damage involving $50 \%$ and $<75 \%$ of cortical tubules $(+++)$.

Grade 4: Tubular damage involving $75 \%$ of cortical tubules $(++++)$.

\section{Statistical analysis}

Mean \pm SE was calculated for each group. Normality of the data was assessed using Kolmogorov-Smirnov test. Statistical analysis was done using t-test for normally distributed data and using Mann-Whitney test for nonnormal data. P-values $<0.05$ were considered as significant. P-values were estimated by referring to appropriate tables.

\section{RESULTS}

\section{Histological effects of gentamicin and W. somnifera treatment on kidney}

Histological evaluation was done in the department of pathology and slides were examined under light microscope. Patchy tubular necrosis along with hyaline cast in the tubular lumina was the predominant morphological feature in GT group. Dropped out tubular cells were also seen in the lumina of some of the renal tubules. Epithelial cells had large vacuoles in it. Some cells had large prominent nuclei suggestive of regenerating cells. The regenerating cells were recognized by enlarged nuclei. Glomeruli were least affected part in kidney. The glomeruli showed mild hyper-cellularity and congestion in most of the sections. There were infiltration of polymorphonuclear leukocytes, lymphocytes, plasma cells and macrophages in renal interistitium particularly around the necrotic tubules. The renal vascular changes were limited to focal area of congestion. 
There were very less damage to tubular epithelium and infiltrations of inflammatory cells less as compared to GT group after 10, 20 and 30 days of pre-treatment. Areas of necrosis were few in number and vascular congestion was also less as compared to GT group. Regenerating cells were densely populated in the slides of 20 and 30 days group. The histological changes were graded as in below mentioned table (Table 1).

Table 1: Histopathological grading of kidney under light microscope at 10, 20 and 30 day duration.

\begin{tabular}{|c|c|c|c|c|c|c|c|c|c|}
\hline \multirow[t]{2}{*}{ Histopathological features } & \multicolumn{3}{|c|}{$\begin{array}{l}\text { Histological grading at } \\
10 \text { days }\end{array}$} & \multicolumn{3}{|c|}{$\begin{array}{l}\text { Histological grading at } \\
20 \text { days }\end{array}$} & \multicolumn{3}{|c|}{$\begin{array}{l}\text { Histological grading at } \\
30 \text { days }\end{array}$} \\
\hline & $\mathbf{C}$ & GT & WST & $\mathbf{C}$ & GT & WST & $\mathbf{C}$ & GT & WST \\
\hline Glomerular congestion & 0 & 3 & 1 & 0 & 2 & 0 & 0 & 1 & 0 \\
\hline Peritubular congestion & 0 & 2 & 1 & 0 & 1 & 1 & 0 & 2 & 1 \\
\hline Epithelial desquamation & 0 & 2 & 2 & 0 & 1 & 1 & 0 & 1 & 1 \\
\hline Blood vessel congestion & 0 & 2 & 1 & 0 & 2 & 1 & 0 & 2 & 1 \\
\hline Interstitial oedema & 0 & 3 & 2 & 0 & 2 & 0 & 0 & 2 & 0 \\
\hline Inflammatory cells & 0 & 3 & 1 & 0 & 2 & 1 & 0 & 1 & 0 \\
\hline Tubular casts & 0 & 2 & 2 & 0 & 1 & 1 & 0 & 1 & 0 \\
\hline Necrosis & 0 & 1 & 0 & 0 & 1 & 0 & 0 & 1 & 0 \\
\hline
\end{tabular}

\section{Kidney weights (in grams)}

Mean kidney weight of GT group was significantly high than the $\mathrm{C}$ group in all test durations. Mean kidney weight of WST group was significantly high as compared to GT group in all test duration but only at 10 days duration as compared to $\mathrm{C}$ group. No significant difference was found between WST and C group at 20 and 30 days duration (Table 2).

Table 2: Weight of kidneys in C, GT and WST groups at different test durations (n=6).

\begin{tabular}{|llll|}
$\begin{array}{l}\text { Duration of treatment } \\
\text { (days) }\end{array}$ & $\begin{array}{l}\text { Kidney weight in C } \\
\text { group (Mean } \pm \text { SE) (in } \\
\text { gram) }\end{array}$ & $\begin{array}{l}\text { Kidney weight in GT } \\
\text { group (Mean } \pm \text { SE) (in } \\
\text { gram) }\end{array}$ & $\begin{array}{l}\text { Kidney weight in WST } \\
\text { group (Mean } \pm \text { SE) (in } \\
\text { gram) }\end{array}$ \\
\hline $\mathbf{1 0}$ & $0.58 \pm 0.04$ & $1.03 \pm 0.10^{\alpha}$ & $0.78 \pm 0.04^{\varepsilon \lambda}$ \\
\hline $\mathbf{2 0}$ & $0.59 \pm 0.03$ & $1.0 \pm 0.12^{\beta}$ & $0.63 \pm 0.04^{\zeta \mu}$ \\
\hline $\mathbf{3 0}$ & $0.56 \pm 0.04$ & $1.01 \pm 0.09^{\gamma}$ & $0.58 \pm 0.02^{\eta v}$ \\
\hline
\end{tabular}

${ }^{\alpha} \mathrm{p}<0.05$ as compared to 10 days of control, ${ }^{\beta} \mathrm{p}<0.05$ as compared to 20 days of control, ${ }^{\gamma} \mathrm{p}<0.05$ as compared to 30 days of control, ${ }^{\varepsilon} \mathrm{p}<0.05$ as compared to 10 days of control, ${ }^{\zeta} \mathrm{p}>0.05$ as compared to 20 days of control, ${ }^{\eta} \mathrm{p}>0.05$ as compared to 30 days of control, ${ }^{\lambda} \mathrm{p}<0.05$ as compared to 10 days of GT, ${ }^{\mu} \mathrm{p}<0.05$ as compared to 20 days of GT and ${ }^{v} \mathrm{p}<0.05$ as compared to 30 days of GT.

\section{DISCUSSION}

Drugs are a major contributor to acute renal failure. Renal toxicity attributive to aminoglycoside is of major clinical concern because of their widespread use. ${ }^{19-21}$ The number of patients developing nephrotoxicity increases with duration of therapy reaching $50 \%$ if the therapy is continued for 14 days or more. ${ }^{22}$ Renal damage caused by gentamicin depends upon the dose and duration of the treatment. Different researchers used different doses, ranging between 8 and $80 \mathrm{mg} / \mathrm{kg} /$ day to produce renal damage. $^{23}$ However, these toxic effects are only associated if the drug is taken five to ten times normal doses. $^{24,25}$

So protection from aminoglycoside induced nephrotoxicity by any means would be of great clinical importance. Gentamicin induced nephrotoxicity model is one of the important and validated models used to study nephroprotective potential of drugs and phytopharmaceuticals. A direct tubular necrosis is also observed during nephrotoxicity.

\section{After 10 days of study}

The mean kidney weights were significantly high in GT group as compared to $\mathrm{C}$ group $(\mathrm{p}<0.05)$. Gentamicin induced nephrotoxicity causes edema and inflammatory changes in proximal tubular epithelial cells thereby increase the kidney weight. ${ }^{26}$ This was also correlated histologically as slides showed intense inflammatory cells in the interistitium and distorted architect of proximal tubular epithelium with marked vasodilatation (Figure 1).

Mean weight of kidney of WST group was significantly high as compared to $\mathrm{C}$ group but significantly low as compared to GT group $(\mathrm{p}<0.05)$. This was also correlated histologically as necrosis was very few and hyaline cast in the tubule were infrequent. Inflammatory cells were also less as compared to GT group (Figure 2). W. somnifera roots extract contains withanolides which inhibits cyclooxygenase enzyme, lipid peroxidation and proliferation of tumor cells. Thus it inhibits inflammation by inactivating nuclear factor kappa-B activation. This property is responsible for limiting the inflammation activity to minimal level. ${ }^{27}$ 


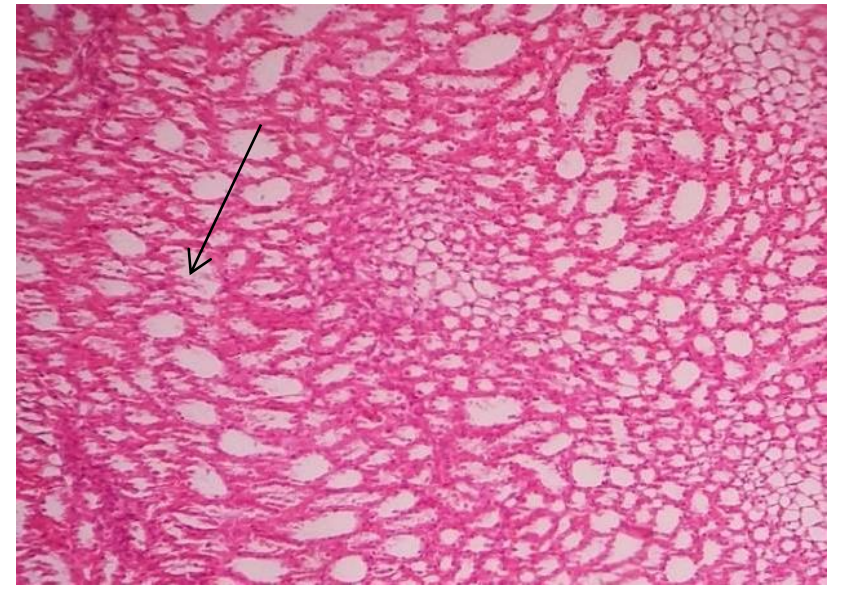

Figure 1: Histology of GT group at 10 days duration showing distorted tubular epithelium (black arrow) and cellular edema.

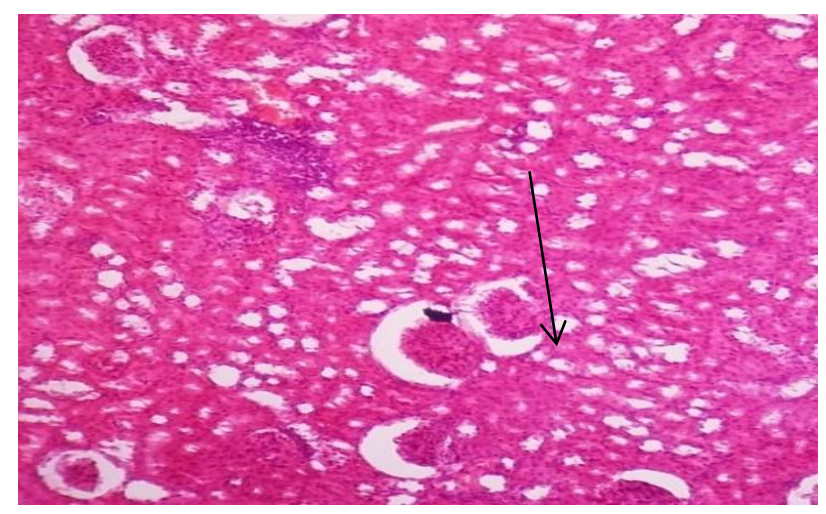

Figure 2: Histology of WST group at 10 days duration showing minimal distortion of tubular epithelium

(black arrow) and cellular edema.

\section{After 20 days of study}

In 20 days duration study kidney weight in GT group was significantly high as compared to $\mathrm{C}$ group $(\mathrm{p}<0.05)$. This was again due to intense inflammatory injury of kidney caused by gentamicin. Reactive oxygen species and reactive nitrogen species generated by gentamicin, plays crucial role in the initiation, and progression of nephrotoxicity. ${ }^{28}$

The mean weight of kidney in WST group was not significantly different to $\mathrm{C}$ group $(\mathrm{p}>0.05)$ but significantly low as compared to GT group $(\mathrm{p}<0.05)$. This means $W$. somnifera as a nephroprotective drug, take some days to work on kidney because the inflammation at 10 days was not comparable to control group. This was also correlated histologically as tubular architect were less distorted and regenerating cells were numerous in number as compared with 10 days slide of WST group (Figure 3). On looking these slides under 10X and 40X magnifications, regenerating cells were recognized by enlarged nuclei and smooth border. Glomerular congestion and interstitial edema was absent though it was present at 10 day duration.

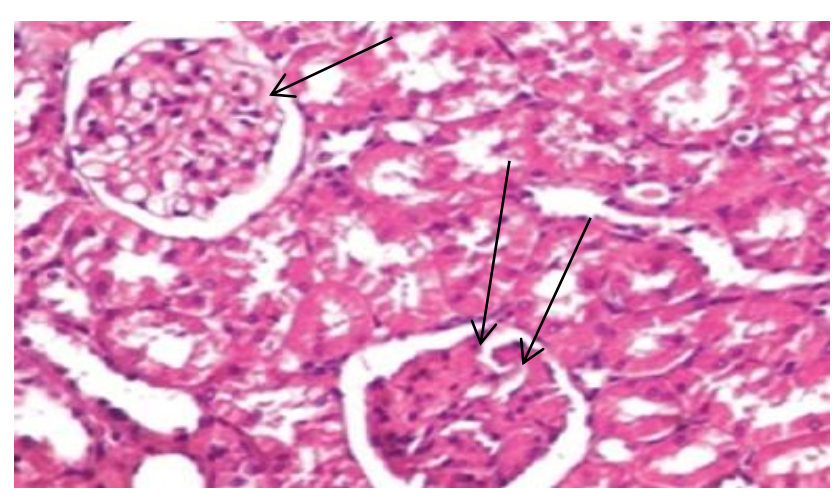

Figure 3: Histology of WST group at 20 days duration showing inflammatory cells (single black arrow) and near normal tubular epithelium (two black arrow).

\section{After 30 days of study}

As expected the mean kidney weight was significantly high in GT group as compared to $\mathrm{C}$ group because gentamicin was injected in last 5 days only in all test durations. Glomeruli were almost normal in majority of slides. Gentamicin induced nephrotoxicity is characterized by direct tubular necrosis, without morphological changes in glomerular structures. ${ }^{29}$

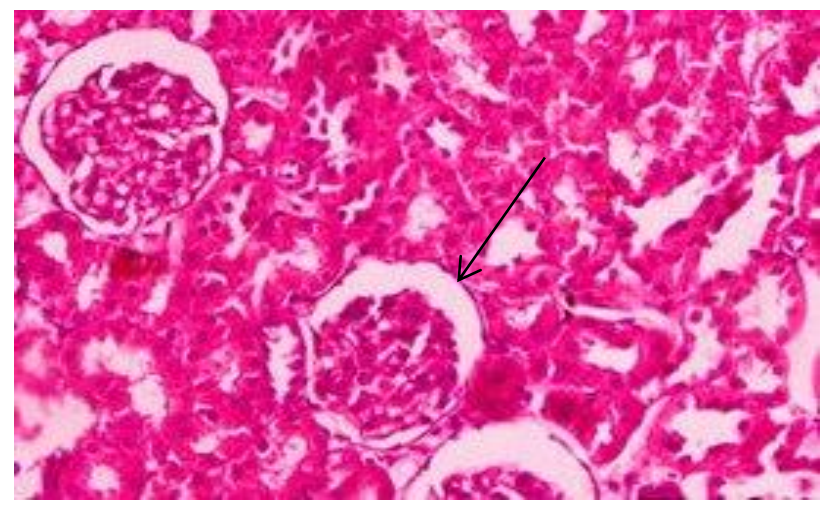

Figure 4: Histology of WST group at 30 days duration showing normal tubular epithelium (black arrow).

Mean weight of kidney in WST group was not different to $\mathrm{C}$ group but significantly low as compared to GT group $(\mathrm{p}<0.05)$. Histologically, there was reorganisation of tubular epithelium and inflammatory cells were absent. Hyaline cast were few in number and vascular congestion was also less as compared to 20 days duration slide of WST treated kidney (Figure 4).

Gentamicin toxicity causes permanent destruction of some of the tubule that reflect as fibrosis and scarring of sub-capsular as well as deeper layer in the kidney. This is the cause of suboptimal kidney function even after near normal structural rebuilt of kidney. ${ }^{18}$ 


\section{CONCLUSION}

This study strengthens the fact that Ashwagandha root extract had antioxidant and free radical scavenging property. This extract can be used as nephroprotection against gentamicin induced nephrotoxicity. We need more study with increase duration of gentamicin injection to see its action on kidney.

Funding: No funding sources

Conflict of interest: None declared

Ethical approval: The study was approved by the Institutional Ethics Committee

\section{REFERENCES}

1. Definition of Aminoglycoside: Available at: www.merriam-webster.com/medical/aminoglycoside. Accessed on 10 September 2018.

2. Swain RA, Kaplan-Machlis B. Therapeutic uses of vitamin $\mathrm{E}$ in prevention of atherosclerosis. Altern Med Rev. 1999;4:414-23.

3. Du XH, Yang CL. Mechanism of gentamicin nephrotoxicity in rats and protective effect of zinc induced metallothionein synthesis. Nephrol Dial Transplant. 1994;9:135-40.

4. Humes HD, Weinberg JM. Toxic Nephropathies: The Kidney. In: Rector FC, Brenner BM. W. B. Philadelphia: Saunders Co.; 1986: 1491-1532.

5. Cuzzocrea S, Mazzon E, Dugo L. A role for superoxide in gentamicin-mediated nephropathy in rats. Eur J Pharmacol. 2002;450:67-76.

6. Al-Majed AA, Mostafa AM, Al-Rikabi AC, AlShabanah OA. Protective effects of oral arabic gum administration on gentamicin-induced nephrotoxicity in rats. Pharmacol Res. 2002;46:445-51.

7. Lakshmi MS, Reddy UK, Rani S. A review on medicinal plant for nephroprotective activity. Asian J Pharm Clin Res. 2012;5:251.

8. Shinwari MI, Khan MA. Indigenous use of medicinal trees and shrubs of Margalla Hills National Park, Islamabad. Pak J Forest. 1998;48:63-90.

9. Gaurav N, Kumar A, Tyagi M, Kumar D, Chauhan UK, Singh AP. Morphology of withania somnifera (Distribution, Morphology, Phytosociology of Withania somnifera L. Dunal). Int J Curr Sci Res. 2015;1:164-73.

10. Dhuley JN. Adaptogenic and cardioprotective action of ashwagandha in rats and frogs. J Ethnopharmacol. 2000;70:57-63.

11. Elsakka M, Grigoreseu E, Stanescu U, Dorneanu V. New data referring to chemistry of Withania somnifera species. Rev Med Chir Soc Med Nat lasi. 1990;94:358-87.

12. Prakash J, Gupta SK, Dinda AK. Withania somnifera root extract prevents DMBA-induced squamous cell carcinoma of skin in Swiss albino mice. Nutr Cancer. 2002;42:91-7.
13. Lavi D, Glotter E, Shro Y. Constituents of Withania somnifera Dun, The structure of Withaferin A. Journal Chem Soc. 1965;30:7517-531.

14. OECD Guidelines for testing chemicals. acute oral toxicity-acute toxic class method. Available at: http://www.iccvam.niehs.nih.gov/SuppDocs/FedDocs /OECD/OECD_GL423.pdf. Accessed on 10 September 2018 .

15. Zbigniew K, Przemystaw K, Morys J. General anaesthesia in rats undergoing experiments on the central nervous system. Folia Morphol. 2001;60(4):235-42.

16. Talib VH. A handbook of medical laboratory technology. 2nd edition. New Delhi: CBS Publishers and Distributors; 2007: 155-167.

17. Erdem A, Gundogan M, Usubutun A, Kilinc K, Erdem S, Kara A, et al. The protective effect of taurine against gentamicin-induced acute tubular necrosis in rats. Nephrol Dial Transplant. 2000:1175-82.

18. Houghton DC, Hartnett M, Cambell-Boswell M, Poeter G, Bennett WA. Light and electron microscopic analysis of gentamicin nephrotoxicity in rats. Am J Path. 1976;82:589-612.

19. Bellomo R. The epidemiology of acute renal failure: 1975 versus 2005. Curr Opin Crit Care. 2006;12(6):557-60.

20. Guo X, Nzerue C. How to prevent, recognize, and treat drug-induced nephrotoxicity. Cleve Clin J Med. 2002;69(4):289-90, 293-4, 296-7.

21. Begg EJ, Barclay ML. Aminoglycosides-50 years on. Br J Clin Pharmacol. 1995;39(6):597-603.

22. Luft FC. Clinical significance of renal changes engendered by aminoglycosides in man. J Antimicrob Chemother. 1984;13(SA):23-30.

23. Lee SM, Michael UP. The protective effect of nitrindipine on gentamicin-induced renal failure in rats. Exp Mol Path. 1985;43:107-14.

24. Tulkens PM. Nephrotoxicity of aminoglycoside antibiotics. Toxicol Letters. 1989;46:107-23.

25. Bennett WM, Elzinger LW, Porter GA. Tubulointerstitial disease and toxic nephropathy. In: Brenner BM, Rector JRFC, eds. The Kidney. Philadelphia: Saunders Co.; 1986.

26. Jeyanthi T, Subramanian P. Nephroprotective effect of Withania somnifera: a dose- dependent study. Renal failure. 2009;31(9):814-21.

27. Ichikawa H, Takada Y, Shishodia S, Jayaprakasam B, Nair MG, Aggarwal BB. Withanolides potentiate apoptosis, inhibit invasion, and abolish osteoclastogenesis through suppression of nuclear factor-kappaB (NF-kappaB) activation and NF-kappa B-regulated gene expression. Mol Cancer Therap. 2006;5(6):1434-45.

28. Uehara T, Miyoshi T, Tsuchiya N, Masuno K, Okada $\mathrm{M}$, Inoue $\mathrm{S}$, et al. Comparative analysis of gene expression between renal cortex and papilla in nedaplatin-induced nephrotoxicity in rats. Hum Exp Toxicol. 2007;26(10):767-80. 
29. Laskshmi BV, Sudhakar M. Protective effect of Zingiber officinale on gentamicin induced nephrotoxicity in rats. Ind J Pharmacol. 2010;6:58-62.
Cite this article as: Kushwaha V. Nephroprotection of Withania somnifera root extract against gentamicin induced nephrotoxicity: a histological evaluation in experimental Wistar rats. Int J Basic Clin Pharmacol 2019;8:2297-303. 